DigiTALCOMMONS @WAYNESTATE-
Michigan Journal of Counseling:

Research, Theory and Practice

Volume 31 | Issue 1

Article 4

$2-1-2003$

\title{
The Impact of Future Orientation on the Avoidance of Teen Pregnancy
}

\author{
Cheryl L. Somers \\ Wayne State University, c.somers@wayne.edu \\ Traci A. Gizzi \\ Livonia Public Schools \\ Stephanie A. Johnson \\ Naperville Community Unit
}

Follow this and additional works at: https://digitalcommons.wayne.edu/mijoc

\section{Recommended Citation}

Somers, C. L., Gizzi, T. A., \& Johnson, S. A. (2003). The Impact of Future Orientation on the Avoidance of Teen Pregnancy, Dimensions of Counseling, 31(1), 17-24. doi:10.22237/mijoc/1044057780

This Article is brought to you for free and open access by the Open Access Journals at DigitalCommons@WayneState. It has been accepted for inclusion in Michigan Journal of Counseling: Research, Theory and Practice by an authorized editor of DigitalCommons@WayneState. 


\section{The Impact of Future Orientation on the Avoidance of Teen Pregnancy}

\author{
Cheryl L. Somers, Ph.D. \\ Wayne State University
}

Traci A. Gizzi, M.A. Livonia Public Schools

Stephanie A. Johnson, M.A. Naperville Community Unit

\section{Introduction}

Despite the relative decline in U.S. teen pregnancy rates in recent decades (Singh \& Darroch, 2000), a high percentage of students continue to be at risk for unintended pregnancy (Warren et al., 1998). In the United States, over one million teenage girls become pregnant annually (Alan Guttmacher Institute, 1994). Of the total pregnancies reported, five out of every six are said to be unintended (Trussel, 1988), suggesting that one out of six may actually intend to become pregnant. Stanton, Black, Kaljee, \& Ricardo (1993) suggest that while adolescents do not think that acquiring condoms was a problem, twothirds of sexually active teens reported never using contraception (Scales, 1987). To some adolescents, parenthood may be a viable and attractive alternative to school and work.

This is especially true of younger adolescents and those from lower socioeconomic (SES) backgrounds (Geronimous \& Korenman, 1992), as well as adolescents who have a history of sexual abuse (Lanz, 1995).

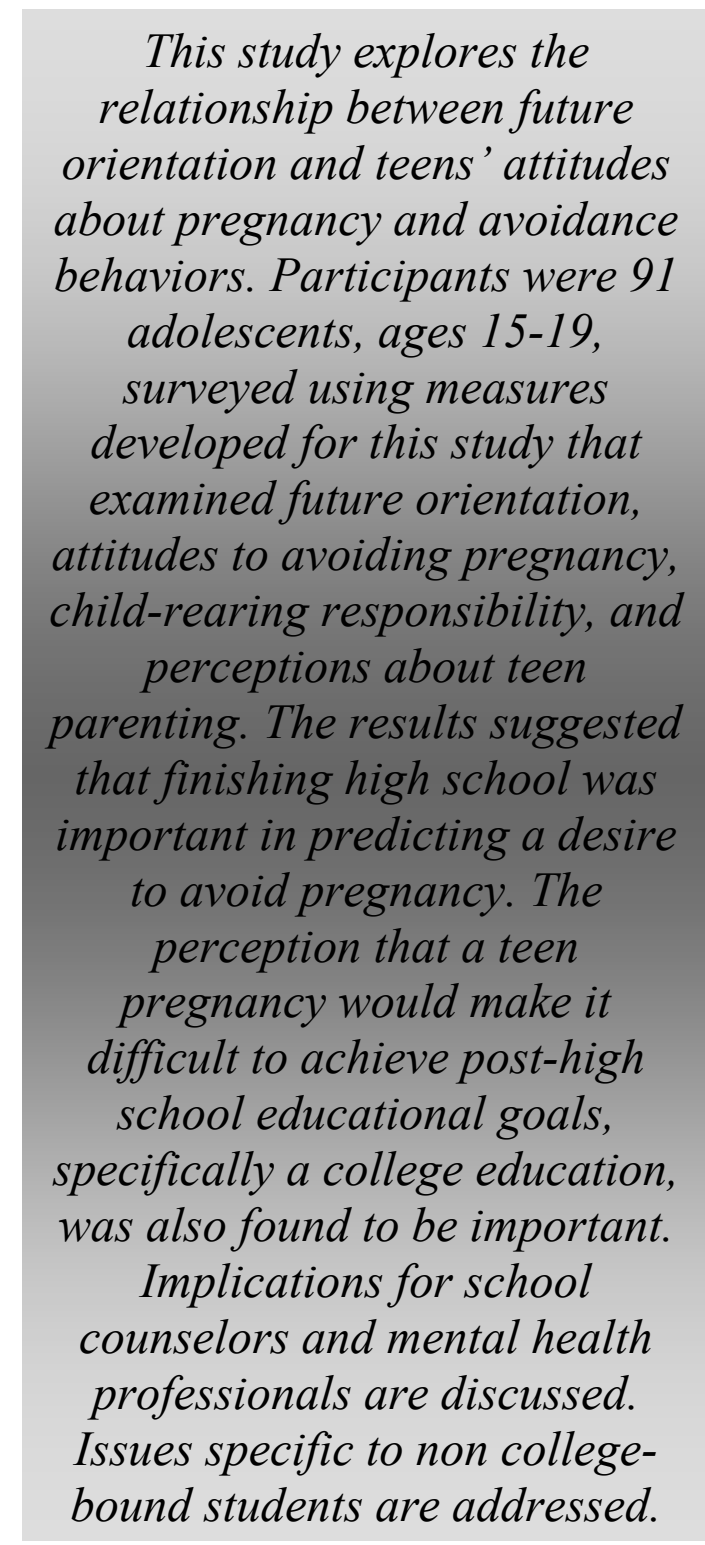

Correspondence concerning this manuscript should be addressed to Cheryl L. Somers, 345 College of Education, Wayne State University Detroit, MI 48202; c.somers@wayne.edu. 
About $77 \%$ of all births among women under age 20 occured to those with family incomes significantly less than the poverty level (Trussel, 1988). A majority of teen mothers in this study were raised in single parent homes and received public aid.

Although teens that come from a low income-level family are the group most likely to get pregnant, teens at every SES level have reported pregnancies. Teen pregnancy has negative outcomes for all groups of people. For example, Baber (1994) concluded that teenage pregnancy is related to poor perinatal outcomes, low educational achievement, unemployment, welfare dependency, repeat pregnancy, parenting problems, marital discord, and greater likelihood of divorce. Several studies focused on the negative consequences to the children of teen parents. For example, children of teens were more likely to die as infants (Geronimous, 1987), grow up in poverty (Geronimous \& Korenman, 1992), and experience problems in school and drop out (Furstenberg, Brooks-Gunn, \& Morgan, 1987).

Despite these negative consequences, the factors which lead teens to become pregnant remain somewhat unclear. Adolescence is a time of curiosity and experimentation, as well as a time to form identities and become independent and autonomous. However, this quest can lead to risk-taking behaviors that often involve fearlessness and excessive self-centeredness (Adams \& Gullotta, 1989). Students may be bored in school or lack the feeling of achievement. Some students may not even perceive a need for education. Christopher and Roosa (1990), for example, evaluated a sexual abstinence program and found that dropouts expected to have sex on the average of four years earlier than those students who completed the abstinence program. This suggests that students who lack incentive to stay in school are also more likely to engage in risk behaviors that may lead to teen pregnancy. A lack of orientation toward the future, including having plans and goals, is likely an important predictor of motivation to avoid pregnancy. Gordon (1996) suggested that "[t]he combination of low academic achievement leading to a desire to drop out of school, low socioeconomic status, and lack of available jobs may lead to pregnancy as the only responsible solution."

There seems to be a positive relationship between the number of years of school that a student completes and the use of contraception (Wyn, Loewen, Delmore, \& Busca, 1998). If a student has little or no orientation to his/her future, he/she may not avoid those behaviors that often impede school completion. In fact, one study revealed that $43 \%$ of 730 urban teens could not determine whether an unexpected pregnancy at this point would negatively or positively impact their lives (Freeman et al., 1980). Medora \& von der Hellen (1997) speculated that teens who avoid pregnancy "may be more goal oriented, with a stronger sense of their future, and therefore may not idealize romantic relationships, pregnancy, and motherhood as do the pregnant and parenting teens (Medora \& von der Hellen, 1997)."

Thirty years ago, it was suggested that those youths who were focused on achievement tended to work toward those goals and avoid behaviors that would prevent attainment of those goals (Hirschi, 1969). More currently, DiBlasio and Benda (1994) suggested that youths who bonded with their parents adopted their parents' values of achievement and commitment to conventional behavior, and that weak commitment to future goals was a factor in selecting peer groups who were sexually active. Additionally, according to Gordon (1996), the relationship between life goals and avoidance of pregnancy and/or abstinence must be considered if we want to reduce the number of intended teen 
pregnancies. Because teen pregnancy is linked to less educational attainment, it is important for school personnel to understand what motivates teens to avoid pregnancy.

The purpose of the current study was to explore the relationship between future orientation (defined as future plans and goals) and students' attitudes about teen pregnancy, parenting and students' behaviors involved with avoidance of teen pregnancy. Specifically, the research investigated the impact of adolescent future orientation on three variables: 1) selfperceived levels of child-rearing responsibility and readiness, 2 ) attitudes toward avoiding pregnancy, and 3 ) perceptions about what it would be like to be a teen parent. Additional attitudes toward and intentions to avoid teen pregnancy such as were also evaluated. It was expected that those students who planned on completing school and continuing their education would be less likely to desire teen pregnancy and be more likely to use consistent contraception in order to avoid a teen pregnancy. Implications are discussed for those who work directly with adolescents in these most impressionable years of development.

\section{Method}

\section{Participants}

Participants were 91 adolescents (25 males and 66 females), ages 15-19 (mean age $=17.01$ ), from two suburban high schools in the Midwest. They were $90 \%$ Caucasian and $10 \%$ Latino, and primarily middle class as indicated by few free or reduced lunches. Students were enrolled in child development and health classes and $62 \%$ reported having engaged in sexual intercourse.

\section{Measures}

Measures were created for the purpose of this research. At the time of this data collection, the authors were either unaware of other established measures or unable to obtain them. A total of 12 items were included in the four subscales of 1) Future orientation 2) Child-rearing responsibility 3) Attitudes towards avoiding pregnancy, and 4) Perceptions about teen parenting. For all measures, participants used a five-point scale with the following response options: $1=$ strongly disagree, $2=$ disagree, $3=$ not sure, $4=$ agree, and $5=$ strongly agree. For all measures, after reverse coding for consistent directionality, scores were summed and higher scores reflected more desirable attitudes and behaviors. Both Cronbach's alpha and Spearman-Brown corrections were calculated for each subscale. In this case, the Spearman-Brown Prophecy Formula projects internal consistency, assuming the total number of items per subscale is 12 . Coefficients are included in their respective instrument descriptions below.

Future orientation. Future orientation, the independent variable, consisted of the following four items: 1) finishing high school is important to me; 2) I am planning on furthering my education after high school; 3) I believe that having a child would make it harder for me to graduate high school; 4) I believe that having a child would make it harder for me to attend college. The Cronbach's alpha coefficient for the current sample was .55. The Spearman-Brown correction was .81. However, the items were treated as four separate independent variables in the analyses.

Child-rearing responsibility. This dependent measure was designed to tap teens' selfperceptions of their levels of responsibility to rear children at this point in their lives. Three items were included: 1) I believe that I am responsible enough to be a parent right now; 2) I am financially secure enough to be 
a parent right now; 3) I do not know enough about being a parent at this time. Cronbach's alpha was .78 for the sample. The Spearman-Brown correction was .93.

Attitudes toward avoiding pregnancy. This dependent measure was designed to tap teens' feelings about becoming teen parents themselves. Three items were included: 1) I would like to become pregnant/my girlfriend to become pregnant; 2) It would be awful if I/my girlfriend got pregnant; 3) It is very important to me to use contraceptives to protect myself from pregnancy. Cronbach's alpha was .53 for the sample. The Spearman-Brown correction was .81.

Perceptions about teen parenting. This dependent measure was designed to tap teens' perceptions of how they would fare if they were to experience a teen pregnancy. Two items were included: 1) If I/my girlfriend were pregnant, I would be able to care for my child myself; 2) I would still have a good marriage and family life if I had a child as a teenager. Cronbach's alpha was .59 for the sample. The Spearman-Brown correction was .90 .

Other attitudes toward teen pregnancy and intentions to avoid teen pregnancy. An additional seven items which were not included in the above subscales were analyzed as individual dependent variables. These items were: My life would not change if I became pregnant; I think it would be fun to have a baby right now; I think it would be harder to find a future husband/wife if I had a baby; I think that a baby would bring my boy/girlfriend and me closer; I always use some type of contraceptive when having sexual intercourse; I have chosen not to be sexually active because I am concerned that I may become pregnant; I think that I would like to have my first child when I am years old.

\section{Results}

Means and standard deviations of all variables are presented in Table 1 .

Correlation coefficients among variables are presented in Table 2. A separate hierarchical multiple regression analysis was run for each of the dependent measures and individual items for the sample as a whole. The four future orientation items were entered as criterion variables for each analysis. Gender analyses were not done due to the small male sample size. However, one-way Analysis of Variance (ANOVA) revealed no significant gender difference in the total future orientation subscale, or in three of the items. On the item "I am planning on furthering my education after high school", females' scores were slightly higher than males (4.45 versus 3.96, respectively) $(\mathrm{F}=3.97, \mathrm{df}=1,89 ; \mathrm{p}=.049)$.

Table 1: Means and Standard Deviations of Primary Variables

\begin{tabular}{|l|c|c|}
\hline \multicolumn{3}{|c|}{ Future Orientation measures } \\
\hline \multicolumn{2}{|c|}{$\mathrm{M}$} & $\mathrm{SD}$ \\
\hline Importance of finishing high school & 4.86 & .38 \\
\hline $\begin{array}{l}\text { Intentions to pursue post high school } \\
\text { education }\end{array}$ & 4.32 & 1.07 \\
\hline $\begin{array}{l}\text { Perceived interference of pregnancy } \\
\text { with high school completion }\end{array}$ & 4.54 & .91 \\
\hline $\begin{array}{l}\text { Perceived interference of pregnancy } \\
\text { with college attendance }\end{array}$ & 4.47 & .77 \\
\hline \multicolumn{3}{|c|}{ Depent measures } \\
\hline Child-rearing responsibility (2 items) & 8.63 & 1.56 \\
\hline $\begin{array}{l}\text { Attitudes toward avoiding pregnancy (3 } \\
\text { items) }\end{array}$ & 12.72 & 2.25 \\
\hline $\begin{array}{l}\text { Perceptions about teen parenting (3 } \\
\text { items) }\end{array}$ & 7.65 & 1.74 \\
\hline
\end{tabular}

Note. $\underline{n}=91$. Means for the dependent measures reflect sums of responses for the number of items in each subscale.

Teens' perceived level of child-rearing responsibility was not significantly predicted by any of the future orientation variables $\left(\mathrm{R}^{2}\right.$ $=.05 ; \mathrm{p}=.40)$. Attitudes toward avoiding pregnancy were predicted by both a greater importance placed on finishing high school $\left(\mathrm{R}^{2}=.32 ; \mathrm{p}=.052\right)$ and a greater perception that having a child would make it harder to attend college $\left(\mathrm{R}^{2}=.05 ; \mathrm{p}<.001\right)$. 
Perceptions about teen parenting was predicted by a greater perception that having a child would make it harder to attend college $\left(\mathrm{R}^{2}=.28 ; \mathrm{p}<.001\right)$.

Analyses involving the individual items as dependent variables revealed that a stronger perception that having a child would make it harder to finish high school was significantly predictive of greater perceived difficulty in finding a future partner or spouse $\left(\mathrm{R}^{2}=.16 ; \mathrm{p}<.01\right)$. Additionally, stronger endorsement of the item "I believe that having a child would make it harder for me to attend college" was significantly predictive of increased rejection of the idea that a baby can be a mechanism to bring a romantic relationship $\operatorname{closer}\left(\mathrm{R}^{2}=.16 ; \mathrm{p}<.01\right)$. None of the other individual items were predicted by the future orientation variables.

\section{Discussion}

The purpose of this study was to explore whether being oriented toward the future, which included future plans and perceptions of how a teenage pregnancy would affect those plans, was predictive of teen pregnancy attitudes and intentions. However, none of the future orientation variables predicted teens' perceptions of how responsible they feel that they are to be rearing children at this point in their lives. The data does indicate that the more that students felt that it was important to finish high school, the more likely they were to hold attitudes that they desired to avoid a teen pregnancy. Simply valuing high school completion did not significantly predict any of the other outcome variables. Apparently, the perception that a teen pregnancy would make it more difficult to attend college was more important in predicting outcome variables. A stronger endorsement of that perception significantly predicted both the desire to avoid teen pregnancy and a more
Table 2: Correlations among primary variables

\begin{tabular}{|c|c|c|c|c|c|c|c|}
\hline & 1 & 2 & 3 & 4 & 5 & 6 & 7 \\
\hline $\begin{array}{l}\text { Importance of } \\
\text { finishing high } \\
\text { school }\end{array}$ & $\begin{array}{l}- \\
-\end{array}$ & .46 & .13 & .42 & $\begin{array}{l}-0.9 \\
\end{array}$ & .39 & $.26^{*}$ \\
\hline $\begin{array}{l}\text { Intentions to } \\
\text { pursue post } \\
\text { high school } \\
\text { completion }\end{array}$ & & -- & -0.1 & .30 & .03 & .19 & .14 \\
\hline $\begin{array}{l}\text { Perceived } \\
\text { interference of } \\
\text { pregnancy } \\
\text { with high } \\
\text { school } \\
\text { completion }\end{array}$ & & & -- & .52 & -.11 & .19 & $.23^{*}$ \\
\hline $\begin{array}{l}\text { Perceived } \\
\text { interference of } \\
\text { pregnancy } \\
\text { with college } \\
\text { attendance }\end{array}$ & & & & -- & -.19 & .53 & .52 \\
\hline $\begin{array}{l}\text { Child-rearing } \\
\text { responsibility }\end{array}$ & & & & & -- & -.15 & .03 \\
\hline $\begin{array}{l}\text { Attitudes } \\
\text { toward } \\
\text { avoiding } \\
\text { pregnancy }\end{array}$ & & & & & & -- & .36 \\
\hline $\begin{array}{l}\text { Perceptions of } \\
\text { teen parenting }\end{array}$ & & & & & & & -- \\
\hline
\end{tabular}

realistic perception of what life would be like after a teen pregnancy.

A stronger future orientation significantly predicted two of the individual items reflecting teen pregnancy attitudes and avoidance behaviors. The importance of finishing high school predicted greater perceived difficulty in finding a future partner after a teen pregnancy. Also, students who perceived a teen pregnancy as an impediment to college plans were more likely to reject the idea that a baby is a way to bring a relationship closer. Future orientation did not predict other outcomes such as contraceptive use among sexually active teens, chosen abstinence for fear of pregnancy, or age at which teens would like to first bear children.

Those teens who believed that a teen pregnancy would impede college plans had more negative reactions to the thought of becoming pregnant as teenagers and desired pregnancy avoidance via contraceptives. They also had a more realistic understanding of what it would be like to manage childrearing as teenagers. A more realistic outlook was also evident through rejection 
of ideas that may be common among more immature pregnant and non-pregnant teens, i.e., that a baby brings relationships closer. These findings not only reflect more maturity on the part of the college bound teens, but it appears that teens realize that a teen pregnancy would make it more difficult to attend college. In the current data, there also appeared to be a slight relation between future orientation and age. A low but positive correlation (.34) was found between age and recognizing that an early pregnancy would be an impediment to post-high school education. This suggests that cognitive and social maturity, typically related to age, may also be key variables that must be factored into prevention and intervention efforts with adolescents.

The challenge for those who work with early adolescents will perhaps be greater, in that during this stage of cognitive development, adolescents' thought processes and perceptions often contain egocentric ideas (e.g., "bad things happen to others, but not to me") and a lack of ability to plan for the future and hypothesize about possibilities (e.g., Steinberg, 2002). Interventions may need to consider including components that provide a realistic perspective of parenting in general, and especially of teenage parenting, as well as components that encourage the growth of hypothetical reasoning skills. Lower levels of abstract reasoning are likely to be related to increased risk-taking behaviors (Orr \& Ingersoll, 1995). Better developed abstract thinking would help kids to perceive future possibilities, and future orientation would allow students to consider future options (Gordon, 1996). At later stages of cognitive development, teens may see a baby as competing with future career plans (Gordon, 1996), and therefore, commit to avoiding a pregnancy.

Implications for non college-bound adolescents as a whole are significant, as they are likely to need guidance toward some other future orientation in order to increase their motivation to avoid teen pregnancy. In this study, concerns about finishing high school and that a teen pregnancy would make it harder to do so, were related only to concerns about a baby interfering with finding a future spouse, and were not related to realistic ideas about the burdens of child-rearing, especially at young ages. The challenges for sex education curricula are significant. Not only is traditional sex education limited to biological education, but it tends to come in a "one size fits all" package. Educators must focus on the importance of meeting the needs of all students, including the relatively large percentage of students who are not bound for college. It is possible that this group has a different perspective on the importance of avoiding pregnancy, may accept education about it differently, and is likely to need assistance in finding motivations other than college plans in order to avoid pregnancy.

Limitations of the study must also be addressed. Although more work is needed on the psychometric properties of the measures, the alphas were relatively acceptable suggesting that the items are reliable at a moderate to moderately-high level. Future research should continue to modify and improve these measures in an effort to gain a solid understanding of the dynamics among the variables of interest in this study. In this study, males and females did not differ overall on their future orientations, and were included together in the analyses. However, another limitation of this study includes the homogeneous sample of primarily Caucasian and female adolescents. More male adolescents should also be encouraged to participate, so that gender comparisons can be made with a larger sample. Additionally, a more direct consideration of the non college-bound 
would significantly build on this study. Interpretations should consider these limitations, and future research should attempt to minimize or avoid these limitations.

Overall, teen pregnancy is a complicated social problem. It is deeply intertwined with poverty, and with the sexual and interpersonal relationships of disadvantaged teens. This may help to explain why shortterm programs are generally not successful at reducing teen pregnancy. Compounding the problem is that pregnancy avoidance programs and abstinence programs are not effective if the adolescents want to become pregnant (Gordon, 1996). It has been purported that a focus on future goals will allow postponement of sexual activity and by postponing sexual activity adolescents will be able to make better-informed decisions (Rossi, 1997). The current findings add to our understanding of whether or not future plans/goals contribute to the avoidance of teenage pregnancy, and the implications for school curricula and interventions by parents, health professionals, and educators are significant. The school counselor is one who may be in an ideal position to offer relevant preventive services. Most specifically, school counselors will likely benefit from this information by enhancing their awareness and understanding of issues that influence adolescents' decisions regarding risky sexual activity and their future goals and plans.

\section{References}

Adams, G., \& Gullotta, T. (1989). Adolescent life experience. Pacific Grove, CA: Brooks/Cole.

Alan Guttmacher Institute. (1994). Sex and America's teenagers. New York: Author.

Baber, K. (1994). Adolescent pregnancy and parenthood. In S. J. Price, P. C. McKenry, \& S. Gavazzi (Eds.), Vision 2010: Families and adolescence to adulthood: Change and stability in the lives of young men. Ann Arbor, MI:
Institute for Social Research, University of Michigan.

Christopher, F., \& Roosa, M. (1990). An evaluation of an adolescent pregnancy prevention program: Is "Just Say No" enough? Family Relations, $i, 68-72$.

Di Blasio, F., \& Benda, B. (1994). A conceptual model of sexually active peer association. Youth \& Society, 25, 351-367.

Freeman, E., Rickles, K., Higgins, G. Mudd, E., Garcia, C., \& Dickens, H. (1980). Adolescent contraceptive use: Comparison of male and female Attitudes and information. American Journal of Public Health, 70, 790-797.

Furstenberg, F., Brooks-Gunn, J., \& Morgan, S., (1987). Adolescent mothers and their children in later life. Family Planning Perspectives, 19, 142-151.

Geronimous, A. (1987). On teenage childbearing and neonatal mortality in the United States. Population and Development Review, 13, 245279.

Geronimous, A., \& Korenman, S. (1992). The socioeconomic consequences of teen childbearing reconsidered. Quarterly Journal of Economics, 107, 1187-1214.

Gordon, C. (1996). Adolescent Decision Making: A broadly based theory and it's application to the prevention of early pregnancy. Adolescence, $i, 561-584$.

Hirschi, T. (1969). Causes of delinquency. Berkley: University of California Press.

Kann, L., Warren, C, Harris, W., Collins, J., Williams, B., Ross, J., \& Kolbe, L. (1996). Youth risk behavior surveillance - United States, 1995. Journal of School Health, 66, 365-377.

Lanz, J. (1995). Psychological, behavioral, and social characteristics associated with early forced sexual intercourse among pregnant adolescents. Journal of Interpersonal Violence, 10, 188-200.

Medora, N., \& von der Hellen, C. (1997). Romanticism and self-esteem among teen mothers. Adolescence, 32, 811-823.

Orr, D., \& Ingersoll, G. (1995). The contribution of level of cognitive complexity and pubertal timing to behavioral risk in adolescents. Pediatrics, 95, 528.

Rossi, A. (1997). The impact of family structure and social change on adolescent sexual behavior. Children and Youth Services Review, 19, 369400.

Scales, P. (1987). How we can prevent pregnancy (and why it's not the real problem). Journal of Sex Education and Therapy, 13, 12-15.

Singh, S., \& Darroch, J. E. (2000). Adolescent pregnancy and childbearing: Levels and trends 
in developed countries. Family Planning Perspectives, 32, 14-23.

Stanton, B., Black, M., Kaljee, L., \& Ricardo, I. (1993). Perceptions of sexual behavior among urban early adolescents: Translating theory through focus groups. Journal of Early Adolescence, 13, 44-66.

Steinberg, L. (2002). Adolescence (6th Ed.). New York: McGraw-Hill.

Trussell, J. (1988). Teen pregnancy in the United States. Family Planning Perspectives, 20, 262-272.
Warren, C. W., Santelli, J. S., Everett, S. A., Kann, L., Collins, J. L., Cassell, C., Morris, L., \& Kolbe, L. J. (1998). Sexual behavior among U.S. high school students, 1990-1995. Family Planning Perspectives, 30, 170-172.

Wyn, K., Loewen, I., Delmore, T., \& Busca, C. (1998). Adolescent oral contraceptive use: factors predicting compliance at 3 and 12 months. The Canadian Journal of Human Sexuality, 7, 1-8. 